\title{
The simple life
}

COLTENE believes that there are always ways to do things more simply, more efficiently for upgraded dentistry. It offers dentists high-quality, hardworking

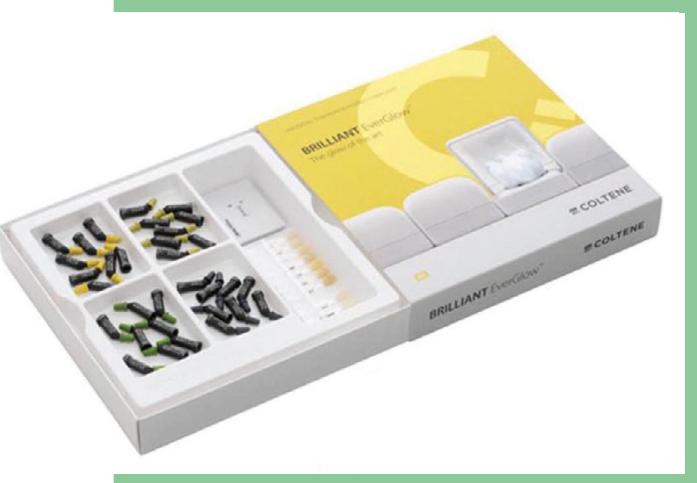

restorative products that are adaptable and uncomplicated.

With its BRILLIANT EverGlow stackable submicron hybrid universal composite, you have a material that will simplify workflows. It can be used for restorations in both the anterior and posterior regions and is just as useful for everyday dentistry as it is for more complex cases.

BRILLIANT EverGlow offers:

$\rightarrow 7$ basic colours - all you need!

$\rightarrow$ Good wettability on the tooth surface for effortless handling

For more on COLTENE, visit www. coltene.com, emailinfo.uk@coltene.com or call 08002545115 .

\section{The right choice for your referrals!}

Have you been presented with a complex endodontic case that needs special attention? Perhaps you have a patient who is scared of treatment because they think it will be painful.

In these scenarios, why not refer to EndoCare?

Our team of endodontic specialists use only the most cutting-edge treatments and products available to guarantee highquality, practically pain-free treatment.

Once we have treated your patient, we always return them to your care with full details of treatment performed, tailored aftercare tips and our suggested next steps.

For further information call EndoCare on 02072240999 pr visit www.endocare. co.uk.

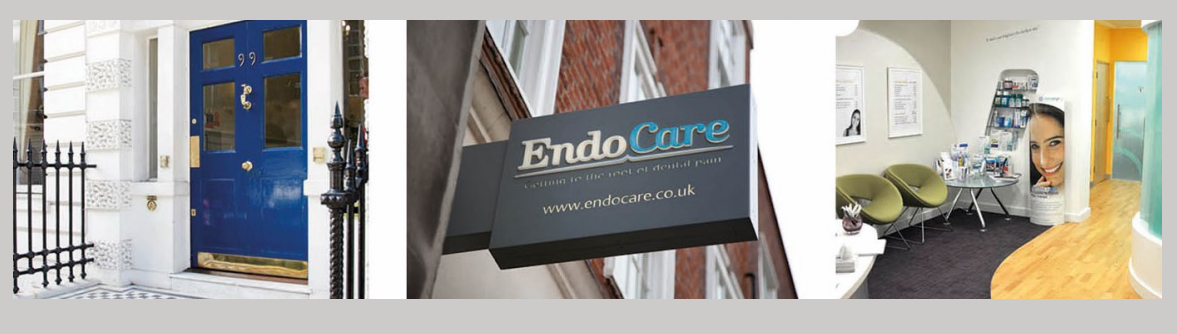

\section{Great-tasting benefits}

A high-quality mouthwash, when used correctly, can give patients the support they need to protect themselves against oral disease.

But for compliance, patients must find it pleasant to use.

'Perio plus' + mouth rinses contain chlorhexidine (CHX) in combination with CITROX ${ }^{\oplus}$, a natural bioflavonoid extracted from bitter oranges with antimicrobial, antioxidant and antiinflammatory properties.

It's an alcohol-free, great-tasting formula with a wealth of benefits and there are options available for all sorts of dental situations. A new study has also indicated that 'Perio plus' regenerate mouthwash has antiviral properties, with evidence to support its relevance in reducing viral load in saliva.

For more information call 01480 862084, email info@curaprox.co.uk or visit www.perioplus.com/uk.

\section{Reference}

1. Carrouel F, Valette M, Gadea E, et al. Use of an antiviral mouthwash as a barrier measure in the sars-cov-2 transmission in adults with asymptompatic to mild COVID-19: a multicentre, randomised, double-blind controlled trial. Clinical Microbiology and Infection 2021: doi.org/10.1016/j. cmi.2021.05.028.
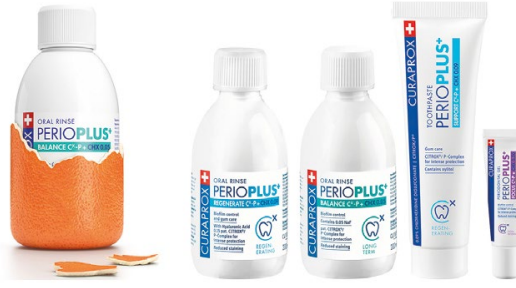

\section{The only 100\% customised option}

When offering your patients orthodontic treatment, you want to be confident that you can provide a solution that is fully tailored to their needs.

With the Incognito Appliance System from 3M Oral Care, you can guarantee bespoke, predictable treatment every time.

The only $100 \%$ customised, invisible fixed orthodontic appliance system on the market, the Incognito Appliance System

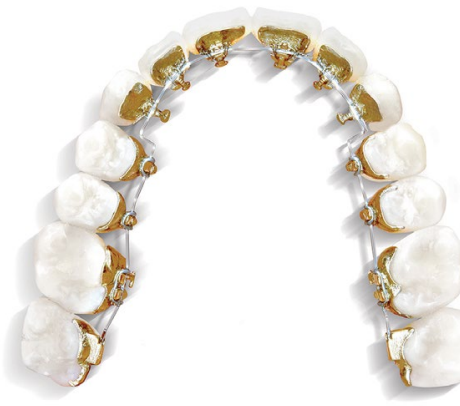

features customised brackets, archwires and bonding trays, helping to deliver a highly personalised approach. Plus, as the system is placed lingually, it ensures patients can continue to live their daily lives with confidence.

For more information, call 0845873 4066 or visit www. 3 m.co.uk/incognito. $3 \mathrm{M}$ representatives remain contactable by phone or via video conferencing. 